\title{
ВЕРСИИ ПРОИСХОЖДЕНИЯ СЛОВА «ФИЛОСОФИЯ»
}

\author{
К.В. Райхерт
}

Общепринятый взгляд на тот или иной предмет или то или иное явление в науке обычно можно найти в учебниках и словарях. Так, в «Новой философской энциклопедии» о происхождении слова «философия» сказано следующее: «По преданию (дошедшему до нас благодаря Гераклиду Понтийскому и Диогену Лаэртию) первое применение термина "философия" принадлежит Пифагору» [6, с. 195]. Именно Пифагор считается создателем слова «философия» $(\varphi \iota \lambda о \sigma о \varphi і \alpha)$ в философской среде за пределами антиковедения. И именно этому обычно / традиционно учат в университетских курсах по философии и истории философии.

Между тем в сообществе историков античной философии, ориентированных на классические филологические методы работы с античными текстами, данная точка зрения в основном воспринимается в негативном ключе $[4,9,11,14]$. Они смотрят не только на то, что сказано в источниках, но и на то, когда эти источники были созданы.

В предлагаемой работе речь пойдет о версиях происхождения слова «философия» в Древней Греции.

\section{Версия 1. Пифагор как автор слова «философия»}

Традиционная версия происхождения слова «философия» восходит к древнеримскому философу Марку Туллию Цицерону (106-43 до н. э.), хотя тот ссылается на Гераклида Понтийского (387-312 до н. э.). В переводе М.Л. Гаспарова этот фрагмент выглядит так: 
По словам Гераклида Понтийского, виднейшего ученого и ученика Платона, когда-то Пифагор во Флиунте вел ученую и красноречивую беседу с флиунтским правителем Леонтом; Леонт так поразился уму и красноречию собеседника, что спросил, откуда у него такие знания; а Пифагор ответил, что никаких знаний он за собой не знает, а просто он философ, то есть «любомудр» $[8$, с. 325].

Между тем перевод Гаспарова не совсем точен; он содержит дополнительную интерпретацию оригинального фрагмента. В оригинале нет пояснения, кто такой философ («любомудр»). Кроме того, в тексте оригинала речь идет не о «знаниях», а об «искусстве» (на латыни ars).

Вот оригинальный фрагмент:

Quem, ut scribit auditor Platonis Ponticus Heraclides, vir doctus in primis, Phliuntem ferunt venisse, eumque cum Leonte, principe Phliasiorum, docte et copiose disseruisse quaedam. cuius ingenium et eloquentiam cum admiratus esset Leon, quaesivisse ex eo, qua maxime arte confideret; at illum: artem quidem se scire nullam, sed esse philosophum [Cic. Tusc. 5.8].

Вся трудность для переводчика / интерпретатора здесь заключается в том, что есть только текст на латинском языке, - этот текст является пересказом Цицерона того, что он прочитал и что он понял у Гераклида Понтийского, чей текст на древнегреческом языке современным антиковедам недоступен.

Приблизительный перевод фрагмента текста Цицерона может выглядеть следующим образом:

Как пишет Гераклид Понтийский, знатный ученый и ученик Платона, когда-то он [Пифагор] прибыл во Флиунт и долго беседовал со знанием дела с Леонтом, правителем флиунтцев. Леонт был поражен его умом и даром речи, поэтому попросил его назвать то искусство, на которое он так твердо полагался. Он ответил, что со своей стороны никаких искусств не знает, но является философом.

Здесь еще раз: оригинальный текст показывает, что пояснения, кто такой философ («любомудр»), нет. Не идет речь и о знаниях; Цицерон использует слово ars, но ни cognitio, ни scientia, ни disciplina, ни experientia, ни mathesis, ни notitia, ни scientiarum summa, ни cognoscibilia universa, ни cuncta scibilia, ни ingenium, ни sapientia, ни даже prudentia. По тексту Пифагор отрицает, что владеет ars, однако называет себя «философом». Этот момент необычен в том плане, что философия противопоставляется ars, то есть в тексте дают четко 
понять, что философия не является ars. Здесь следует привести такое соображение: даже если бы в тексте Цицерона шла речь о знаниях, все равно не имело бы смысла противопоставлять философию знанию; философия как «любовь к мудрости» может быть противопоставлена только мудрости, чтобы прояснить отличие философии от мудрости. Так как Цицерон писал на латыни, то он вполне мог оказаться в затруднении при попытке передать на латыни древнегреческое бофí $\alpha$. Ведь бофі $\alpha$ обладает не только переводным значением «мудрость», но и, например, значением «мастер в каком-либо деле (в том числе искусстве)». Не случайно словом боџо́ «мудрец» древние греки обозначали мастера в своем деле, эксперта, специалиста. Отсюда возможно допустить, что Цицерон попытался через латинское слово ars передать древнегреческое слово бофí $\alpha$, а ему уже противопоставил

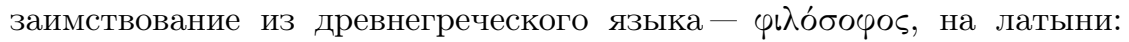
philosophus. Если это соображение верно, то здесь отчетливо проглядывается взгляд Платона на философию, предложенный в его диалоге «Пир», в котором речь Сократа посвящена гению Эроту, который в силу отсутствия у него красоты и мудрости стремится к обретению этих самых красоты и мудрости, причем само это стремление есть любовь [Pl. Symp. с. 199-212]. Это делает Эрота покровителем философов, которые также любят / стремятся к мудрости, к ее овладению. Самой же мудростью обладают только боги. Они - подлинные мудрецы. В таком случае истоки истории Гераклида Понтийского следует искать в философии Платона, а саму историю считать платонической выдумкой.

Я здесь должен обратить внимание читателя данной работы на то, что это всего лишь соображение и что, повторяя еще раз, текст Цицерона написан на латыни, а оригинальным текстом на древнегреческом языке Гераклида Понтийского современное антиковедение не располагает. Еще одним важным моментом может быть тот факт, что я, как и другие антиковеды, не могу знать, насколько компетентным был римлянин Цицерон в знании и владении древнегреческим языком. Все сказанное выше порождает определенный скептицизм в отношении разбираемой версии происхождения слова «философия».

\section{Версия 2. Слово «философия» возникло во второй половине $\mathrm{V}$ века до нашей эры}

Большинство современных историков античной философии разделяют точку зрения, что слово «философия», как минимум, уже упо- 
треблялось в 430 году до н.э. [14]. В качестве подтверждения этой точки зрения приводятся фрагменты двух текстов того времени.

Первый фрагмент взят из работы «О древней медицине», автором которой предположительно является Гиппократ (ок. 460 - между 377 и 356 до н. э.) и которая была написана приблизительно в 400 году до н. э.:

Теперь же некоторые врачи, как впрочем, и ученые люди, утверждают, что невозможно знать медицину, не зная, что такое человек. Однако разговоры этих людей касаются философии ( добие того, что Эмпедокл или другие авторы писали в старину о природе, объясняя, что есть человек, как он появился и как он устроен. Однако я думаю, что все, что было сказано или написано такого рода о природе некоторыми учеными людьми или врачами, имеет мало общего с искусством врачевания. И я думаю, что для получения довольно точного знания о природе, лучшего источника, чем врачевание, нет [13, c. 52].

Другой фрагмент взят из речи «Похвала Елене» Горгия (483-380 до н. э.), написанной приблизительно после 427 года до н. э.:

\begin{abstract}
Что убежденье, использовав слово, может на душу такую печать наложить, какую ему будет угодно, - это можно узнать, прежде всего, из учения тех, кто учит о небе: они, мненьем мненье сменяя, одно уничтожив, другое придумав, все неясное и неподтвержденное в глазах общего мнения заставляют ясным явиться; затем - из неизбежных споров в судебных делах, где одна речь, искусно написанная, не по правде сказанная, может, очаровавши толпу, заставить послушаться; а в-третьих - из прений философов, где открываются и мысли быстрота, и языка острота: как быстро они заставляют менять доверие к мнению! (перевод С. Кондратьева) [3, с. 29].
\end{abstract}

Как можно видеть, обе работы датируются после 430 года до н. э. Однако современные антиковеды не объясняют, откуда вообе взялась дата 430 год до н. э. Далее я хочу предложить свою версию происхождения слова «философия», которая может ответить на вопрос, откуда взялась дата 430 год до н. э. как дата возникновения слова «философия».

\title{
Версия 3. Перикл как автор слова «философия»
}

Немецкий классический филолог Герман Дильс (1848-1922) в своих лекциях по истории древнегреческой философии сообщил, что впервые слово «философия» встречается в надгробной речи Перикла [11, c.1]. Правда, Г. Дильс потом уточнил, что, скорее всего само слово 
«философия» придумал историк Фукидид и вписал его в речь Перикла [11, с. 1]. Почему Г. Дильс так считал, он не объяснил. Тем не менее, у историка И.Е. Сурикова можно найти ответ:

Однако в целом «афинский олимпиец» [Перикл] относился, повторим, еще к ораторам «старого стиля», которые опирались главным образом на импровизацию и не записывали своих речей. Именно поэтому, кстати, мы не имеем никаких аутентичных произведений Перикла. [...] Несколько речей Перикла, передаваемых Фукидидом, не должны, разумеется, рассматриваться как заведомо недостоверные (всетаки историк в молодости слушал самого «первого гражданина»), но они все-таки не могут восприниматься и как реальное, точное отражение того, что говорит лидер полиса. Это - пересказ по памяти, к тому же со значительными изменениями, внесением элементов собственных взглядов Фукидида и пр. [7, с. 291].

Тем не менее, версия о Перикле как авторе слова «философия» имеет право на жизнь. Я постараюсь это обосновать далее.

Я полагаю, что возникновение слова «философия» может быть связано с так называемым «кружком Перикла». Достаточно полно кружок Перикла описан историком Э.Д. Фроловым:

Одним из самых примечательных явлений в общественной жизни Афин V века до н. э. был кружок выдающихся представителей культуры, сложившийся вокруг признанного лидера афинской демократии Перикла [1, с. 24].

И дальше:

Разумеется, Периклу, как и любому другому афинскому гражданину, не возбранялось иметь личных друзей, однако сложившееся вокруг него сообщество по своему составу и значению далеко превосходило любое частное содружество. Античная традиция с явным интересом относилась к этому личному окружению знаменитого политика и донесла до нас длинный ряд имен людей, стоявших рядом с ним и помогавших ему своими советами и сотрудничеством. В этом ряду прежде всего можно выделить группу интеллектуальных наставников и советников Перикла [1, с. 28].

Э.Д. Фролов называет в качестве «наставников и советников Перикла» следующих людей: политика и музыканта Дамона, философов Зенона Элейского, Анаксагора из Клазомен и софиста Протагора из Абдер. В кружок входили философ Сократ, историк Геродот, драматург Софокл, архитектор Гипподам Милетский, архитектор-скульптор Фидий, механик Артемон.

Любопытно, что всех названных выше людей можно назвать словом «софисты», и вот почему: 
Обычное использование греками $\mathrm{V}$ века до н. э. термина бофьбт́́s [coфист] сводилось к обозначению многих «мудрых мужей» древности, и он охватывал очень широкий класс людей. Это могли быть представители частных профессий, отличительной чертой которых было странствование из города в город и которые, вероятно, могли в обмен за определенную плату не только демонстрировать свое искусство, но и давать разъяснения или даже читать лекции о своем предмете, хотя в целом такая практика не была характерна для цеховой культуры.

Помимо ремесленников и мастеровых (строителей, архитекторов, скульпторов и проч.) это могли быть поэты, такие как Гомер, Гесиод или Ксенофан, музыканты, рапсоды, люди, сведущие в искусствах, предсказаниях, гаданиях, представители традиции Семи мудрецов, ранние философы. Этот термин мог быть даже применим к таким фигурам, как Прометей, с которыми, возможно, связано ключевое для софистики значение слова бофюти́s - делающий людей мудрыми или опытными. Именно в контексте этого оттенка значений и расхо-

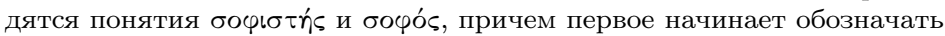
не просто человека, обладающего какой-либо мудростью, но человека, способного эту мудрость преподать, то есть «учителя мудрости», на что, кстати, указывает и частое применение этого термина к поэтам, чья роль в полисе, главным образом, сводилась именно к наставлению граждан в разного рода моральных и вообе житейских практиках, а не их развлечению [2, с. 31-32].

Не менее важным фактом в биографии Перикла является то, что самым близким другом (да и не только) для Перикла была гетера Аспасия:

С именами Перикла и Аспасии связано в истории античности рождение нового института - открытого литературно-политического салона, которому суждено было сыграть важную роль также и в общественной жизни новой Европы. Это была бросавшаяся в глаза новация, и, как это всегда бывает, она дорого обошлась своим инициаторам. Открытая связь с бывшей гетерой, пестрый круг друзей, включавший, помимо афинских граждан, большое число чужеземцев, непрерывная череда встреч и собраний в доме, доступ в который не был заказан ни одному мало-мальски оригинальному человеку, - все это резало глаза и вызывало неодобрение у ревнителей благочинной старины. Но самое главное состояло в непрерывном росте влияния и авторитета сложившегося вокруг Перикла кружка. Исходившие от его членов новые интеллектуальные веяния, социальные и политические инициативы, строительные и художественные проекты будоражили афинскую жизнь, возбуждая подозрения и опасения в консервативной массе народа [1, с. 32-33].

Такое отношение афинян к членам кружка Перикла коррелирует с отношением афинян к софистам: 
Афиняне, как впрочем, и жители многих других полисов, с подозрением относились к интеллектуалам и вообще ученым мужам и

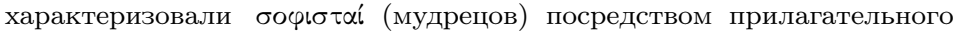

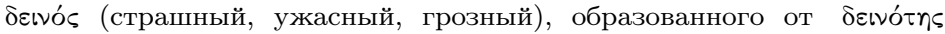
(мощь, власть, страшная сила), позаимствовав этот эпитет у таких явлений, как оружие, водовороты, львы, молнии и проч. В народном словоупотреблении значения бофо́ и и бєเvós смешиваются: египтяне устрашающи в искусстве военной хитрости, Прометей-в искусстве избегать трудностей, хороший возница - в умении управлять колесницей, софист же устрашающ в своем искусстве овладевать умами людей и передавать свое знание, он «ужасно умный». Иными словами, бофıбт́́s - это отглагольное существительное, обозначающее деятеля, и деятельность софистов состояла в том, чтобы сделать других настолько же искусными и опытными в практиковании мудрости $[2$, c. 32].

В любом случае подозрительное к кружку Перикла отношение афинян привело к судебным процессам против его участников:

Начавшиеся против друзей Перикла судебные процессы носили тем более острый характер, что они опирались на достаточно широко распространенное в афинском обществе враждебное отношение к этому кружку, чья новаторская деятельность бросала вызов традиционному укладу жизни. Теперь общественная критика обрушилась на все сферы практической и просветительской деятельности, равно как и на образ жизни соратников Перикла. Одним из первых был предан суду скульптор Фидий, обвиненный в утайке драгоценных материалов (золота и слоновой кости), отпущенных на сооружение колоссальной статуи богини Афины, предназначенной для Парфенона. Когда же факт хищения доказать не удалось, ему было предъявлено новое обвинение в преступлении против религии, поскольку на щите Афины, где была представлена битва афинян с амазонками, художник наряду с мифологическими персонажами посмел изобразить себя самого и своего патрона. Фидий был заключен в тюрьму, где и умер от болезни, так, по-видимому, и не дождавшись суда. Между тем народное собрание даровало донесшему на него Менону (одному из его помощников, по-видимому, метеку) освобождение от всех повинностей (ателию) и поручило стратегам заботиться о его безопасности, - решение, которое нельзя было расценить иначе как подтверждение вины Фидия и выражение недоверия Периклу [1, с. 34].

Наставник Перикла - Анаксагор был привлечен к суду за безбожие и приговорен к смерти, однако Анаксагору удалось сбежать из Афин. Удивительно, что другой участник кружка Перикла - Сократ спустя годы так же, как Анаксагор, был приговорен к смерти за безбожие, только Сократ был казнен. Финальным судебным процессом оказался суд над самим Периклом за превышение полномочий. В данном случае Перикл отделался простым штрафом. 
Так или иначе, кружок Перикла привлекателен тем, что там собирались видные интеллектуалы, можно сказать «софисты»: политики, люди искусства и философы. Это вполне могло сподвигнуть Перикла в надгробной речи 430 года до н. э., представленной во второй книге

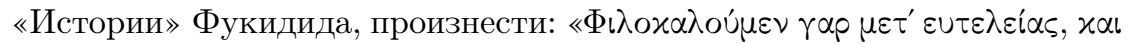

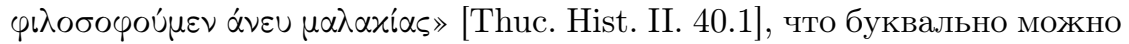
перевести как: «Наша любовь к красоте не приводит нас к расточительству и наша любовь к мудрости не делает нас слабыми». Вот это

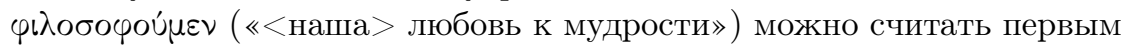
случаем употребления слова фьлобофі́ («любовь к мудрости», «философия»). K тому же Перикл вполне мог называть участников своего

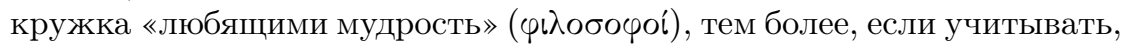

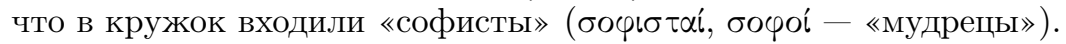

Такова моя гипотеза происхождения слова «философия». Между тем я хочу обратить внимание читателя на один момент, связанный с человеком, который входил в кружок Перикла, а именно: с «отцом истории» Геродотом Галикарнасским (484-425 до н. э.).

\section{Версия 4. Геродот и происхождение слова «философия»}

В первой книге «Истории» Геродот привел содержание легендарной беседы между лидийским царем Крезом (595-546 до н. э.) и одним из Семи мудрецов, афинянином Солоном (между 640 и 635 - около 559 до н. э.). В уста Креза Геродот в ходе этой беседы вложил следующие слова:

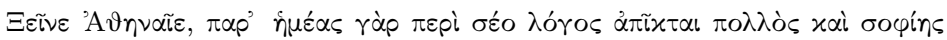

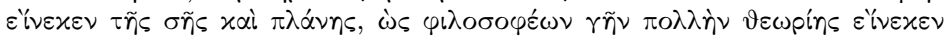

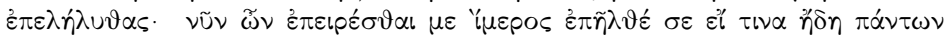

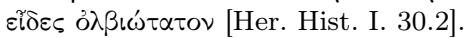

Перевести это можно приблизительно так:

Гость из Афин, мы много слышали о твоей мудрости и твоих путешествиях, которые ты совершил из любви к мудрости ( чтобы повидать мир. Я хочу спросить тебя, не встретил ли ты уже счастливейшего человека на свете.

Почему же приведенный фрагмент так важен в контексте исследования происхождения слова «философия»? Ответов будет несколько. Первый ответ: фактически «История» Геродота была написана в 440 году до н.э., что вполне может сделать приведенный фрагмент 
самым древним из имеющихся в распоряжении современного антиковедения источников, в котором встречается слово «философия». Конечно, здесь возможны всякие спекуляции, например: Геродот входил в кружок Перикла, поэтому он мог оттуда почерпнуть слово «философия», - отсюда: возникновение слова «философия» можно датировать, как минимум, 440 годом до н.э. Или же наоборот, Геродот был подлинным автором слова «философия», а уже члены кружка Перикла заимствовали слово.

Второй ответ: Геродот, по сути, вводит в оборот новую легенду о происхождении слова «философия». Слово «философия» (любовь к мудрости) было случайно придумано лидийским царем Крезом в беседе с греком Солоном где-то в первой половине $\mathrm{V}$ века до н.э., а далее само это слово уже мог «экспортировать» в Древнюю Грецию Солон. Если принять данную гипотезу, то окажется возможным «подтвердить» гипотезу о Пифагоре: Пифагор (570-490 до н. э.), который достиг своего расцвета-акме (возраст от 30 до 50 лет) уже после смерти Солона (между 640 и 635 - около 559 до н. э.), в беседе с флиунтским правителем Леонтом вполне мог употребить уже устоявшееся слово «философ».

Итак, в настоящей работе были рассмотрены четыре версии происхождения слова «философия». Первая версия связана с именем древнегреческого философа Пифагора Самосского: легенда, изложенная Цицероном на основе текста Гераклида Понтийского, гласит, что Пифагор был автором слова «философия». Само слово «философия» в таком случае должно было появиться приблизительно во второй половине VI века до н.э.

Вторая версия принимается большинством современных антиковедов и основывается на сообщениях софиста Горгия и врача Гиппократа. Согласно этой версии слово «философия» уже употреблялось во второй половине V века до н.э., скорее всего, среди жителей полиса Афины.

Я предложил третью версию, согласно которой автором слова «философия» можно считать афинского политического деятеля Перикла. Само слово «философия» могло возникнуть в рамках деятельности так называемого «кружка Перикла», куда входили видные древнегреческие интеллектуалы, которых можно обозначить словом «софисты» (в широком значении этого слова).

Также я обратил внимание, что возможна четвертая версия происхождения слова «философия». Эта версия связана с именем древне- 
греческого историка Геродота, который упомянул слово «философия» в первой книге своей «Истории», написанной около 440 года до н. э. Данная версия, на мой взгляд, потребует серьезной проработки в будущем.

В завершении я хочу отметить, что ввиду скудости древних источников на современном этапе изучения истории античной философии дать единую версию происхождения слова «философия» оказывается принципиально невозможным, поэтому все вышеприведенные версии пока что остаются всего лишь версиями, - и не более того.

\section{Принятые сокращения:}

Cic. - Cicero, Цицерон (сочинение: Tusc. = Tusculanae Disputationes, Тускуланские беседы).

Her. - Herodotus, Геродот (сочинение: Hist. = Historia, История).

Pl. - Plato, Платон (диалог: Symp. = Symposion, Пир).

Thuc. - Thucydides, Фукидид (сочинение: Hist. = Historiae, История).

\section{Литература}

[1] Альтернативные социальные сообщества в античном мире / Э.Д. Фролов, Е.В. Никитюк, А.В. Петров, А.Б. Шарнина. - СПб. : Издательство Санкт-Петербургского университета, 2002.

[2] Вольф М.Н. Софистика. Горгий Леонтийский: трактат «О не-сущем, или О природе» в современных интерпретациях. - Новосибирск : РИЦ НГУ, 2014.

[3] Горгий. Похвала Елене // Ораторы Греции: пер. с др.-греч. / сост. М. Гаспаров. - М. : Художественная литература, 1985. - С. 27-31.

[4] Paйxерт K.В. Вопрос о происхождении слова «философия» // Вітчизняна та зарубіжна наука на початку другої декади XXI століття. Частина 1 (Історичні науки, Політичні науки, Психологічні науки, Соціологічні науки, Філософські науки, Юридичні науки): міжнародна конференція, м. Київ, 2 березня 2013 року. Київ : Центр наукових публікацій, 2013. - С. 48-50.

[5] Платон. Пир // Платон. Избранные диалоги: пер. с др.-греч. М. : РИПОЛ КЛАССИК, 2001. - С. 329-387. 
[6] Степин В.С. Философия // Новая философская энциклопедия. Т. 4. Т-Я. - М. : Мысль, 2010. - С. 195-200.

[7] Суриков И.Е. Античная Греция. Политики в контексте эпохи. Время расцвета демократии. - М. : Наука, 2008.

[8] Цицерон М.Т. Тускуланские беседы // Цицерон М.Т. Избранные сочинения. - М. : Художественная литература, 1974. - С. 207-357.

[9] Burkert W. Plato oder Pythagoras. Zum Ursprung des Wortes Philosophie // Hermes. - 1960. - № 88. - S. 159-177.

[10] Ciceronis Tusculanae Disputationes. - Vol. I (Books I and II).Cambridge: University Press, 1905.

[11] Diels H. Griechische Philosophie: Vorlesungsmitschrift aus dem Wintersemester 1897/98 (herausgegeben von Johannes Saltzwedel). Stuttgart: Steiner, 2010.

[12] Herodotus graece \& latine. - T.1. - Edinburgi: E Preto Academico impensis Gulielmi Laing, MDCCCVI.

[13] Hippocrates. Ancient Medicine // Hippocrates with the English Translation by W.H. Jones. - L. : Heinemann Ltd.; Cambridge: Harvard University Press, 1957. - P. 1-64.

[14] Laks A. Remarks on the Differentiation of Early Greek Philosophy // Philosophy and the Sciences in Antiquity / ed. R.W. Sharples. Burlington: Ashgate, 2005. - P. 8-22.

[15] Thucydidis Historiae recensuit Carolus Hude. - Vol. 1. Libri I-IV. Lipsiae in aedibus B.G. Teubneri, MCMI.

Надійшла до редакиї̈ 25 лютого 2015 р. 